\title{
Los testimonios del Consulado mexicano en La Habana. Una fuente olvidada para la historia del siglo XIX
}

Laura Muñoz INSTTTUTO MORA

\section{INTRODUCCIÓN}

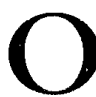

pacados por la importanciaque tradicionalmente han tenido las relaciones mexicanas con Estados Unidos, los vínculos con otras áreas del continente no han sido suficientemente estudiados. Sin embargo, en las últimas dos décadas, el área del Caribe adquirió importancia para la política exterior de México y, paralelamente, los estudios acerca de las relaciones entre ambos se incrementaron. La mayoría de esos estudios ha hecho hincapié en los vínculos establecidos en el periodo colonial. A és- tos los siguen, en importancia y número, los que analizan la época contemporánea a partir de los años posteriores a la revolución cubana. Por último, los trabajos más escasos han sido los que hacen referencia al siglo XIX.

Recientemente, el Archivo General de la Nación (México) ha puesto a disposición de sus usuarios un fondo documental que complementa al del acervo del Archivo Histórico Diplomático de México (Secretaría de Relaciones Exteriores) y que constituye una fuente importante para el estudio de las relaciones de México con el Caribe en el siglo XIX. Se trata de los libros copiado- 
res de la correspondencia del Consulado mexicano en La Habana. Estos libros reflejan todo el periodo que abarca el proceso de formación y consolidación del Estado nacional en México y de la lucha cubana por su independencia. Ambos países sufrieron durante ese periodo, con distintas repercusiones, los embates de la política expansionista de su vecino estaodunidense $y$ el intervencionismo de potencias extranjeras.

No obstante que el uso de este tipo de materiales podría conducir a formarse una visión parcial de esa relación-claro está, en el caso de que ninguna otra fuente fuera consultadaofrece, en cambio, la posibilidad de obtener un pormenorizado relato del desarrollo de esas relaciones desde el punto de vista mexicano y nos permite conocer la posición que México adoptó, sus intereses y sus estrategias.

\section{LAS FUENTES}

El fondo en cuestión está formado por más de 40 tomos que recogen la correspondencia que el Consulado mexicano en La Habana intercambió con la Cancillería en México desde que fue fundado en 1838 hasta $1922 .{ }^{1}$ Aunque no tengo cifras exactas para todo el periodo, considero que la correspondencia fue abundantísima. Un dato revelador de esto es que en 1907 , año en que ya no era cónsul el más pro-

\footnotetext{
${ }^{1}$ El tomo que reúne exclusivamente cartas enviadas desde México es el AGN, L-(729.1-5)-34 correspondiente a 1877. En éste, como en los siguientes casos, sólo se citan algunos libros como ejemplo.
}

lífico de los corresponsales, y en que por otra parte, el intercambio epistolar había descendido considerablemente, el consulado envió a México 596 cartas y recibió de la Secretaría $533 .^{2}$ La comunicación, pues, fue intensa. Primero con la ciudad de México, por ser la sede de la Cancillería, y después, en orden decreciente en importancia, con Veracruz, Progreso, Tampico, Isla Mujeres, Isla del Carmen, Coatzacoalcos y Campeche. ${ }^{3}$

Libros desiguales tanto por su contenido como por su estado de conservación, reúnen en sus páginas un relato detallado de la historia de las relaciones entre los dos países a lo largo de casi un siglo. Cada tomo refleja la idea que de su labor tenían los cónsules que estuvieron al frente de la oficina. Así, encontramos volúmenes con cartas que transmiten gran cantidad de información, al lado de tomos que parecen colección ordenada de memoranda, o bien, libros que se refieren exclusivamente a la actividad económica, mientras que otros sólo hablan de la situación política interna de la isla. Los hay que expresan claramente el interés de México por Cuba, o los que muestran la preocupación por los mexicanos que trabajan en las zonas urbanas y en el campo en aquella isla, etc. Algunos de los volúmenes están formados por más de 800 páginas, y la mayoría no tiene menos de 300 . Cada tomo encierra en sus delgadas páginas de papel cebolla el resultado de la paciente labor de observadores acuciosos.

\footnotetext{
2 AGN, L-(729.1-5)-29,1906-1907.

3 lbid.
} 
Los libros de la correspondencia del Consulado mexicano en La Habana, aunque no son una seria completa -pues faltan los que van de 1856 a 1870-, dan muestra de la variedad de actividades desempeñadas por nuestros representantes y nos permiten rastrear el tipo de asuntos de los que se encargaban esas oficinas. Como se ha dicho, ya constituyen un acervo complementario al que posee el Archivo Histórico Diplomático, donde se guardan los expedientes personales de los cónsules y algunas de sus cartas, $\mathrm{e}$ incluso el tomo correspondiente al año 1896 de la serie de Libros Copiadores. ${ }^{4}$ En conjunto, ambos fondos documentales brindan un conocimiento amplio del desarrollo de los estrechos vínculos entre México y Cuba.

La mayor parte de los libros contienen temas que se vuelven recurrentes y constituyen una guía de los objetivos e intereses de México respecto a Cuba. Además de la correspondencia ordinaria, los inventarios de la Legación y los libros de caja, se hallan los reportes del movimiento marítimo, del tráfico comercial, reseñas e informes económicos y políticos. Su lectura nos proporciona los perspectivas de la acción mexicana. Por una parte, la que percibimos de la labor de los representantes mexicanos en Cuba y de la respuesta de la población a sus actividades y, por otra, la que se infiere de la labor de los funcionarios y autoridades en México, así como de las negociaciones de los cubanos en nuestro país.

${ }^{4}$ AHSRE, exp. LE2266.
Durante algunos años, los intereses de México fueron exclusivamente económicos, pero en otros, predominaron los políticos. A los gobiernos de México, aunque no tuvieran ambiciones expansionistas, les interesaba, además de los beneficios resultantes del buen desarrollo del tráfico comercial, tener una presencia en la región. Más allá del interés por razones de orden econó. mico y geopolítico, Cuba era para México una valiosa fuente de información. ${ }^{5}$

La riqueza de esa información varía en cada uno de los tomos de acuerdo con el autor de las misivas. Destacan por su minuciosidad las redactadas por Buenaventura Vivó (cónsul de 1846 a 1853), por Antonio Hoffman Urquía (de 1866 a 1877) y, de manera especial, las que escribió con pasión y gus. to don Andrés Clemente Vázquez (de 1886 a 1901).

\section{LOS TEMAS}

Como puede apreciarse en el inventa. rio anexo, los temas que podemos identificar en el conjunto documental constituido por los libros copiadores, y que evidentemente preocupaban a la cancillería mexicana, son en primer lugar, la situación política de la isla y el grado de desarrollo de la actividad económica. Por tanto, los informes políticos y las reseñas económicas son los documentos que más abundan en la correspondencia. ${ }^{6}$ La Habana es un

\footnotetext{
5 Véase por ejemplo AHSRE, exp. 11-9-199.

${ }^{6}$ AGN, L-(729.1-5)-12, 1887.1888; -16, 1889 . $1892 ;-22,1896-1898 ;-24,1888-1890 ;-26,1901$ $1902 ;-31,1908-1909 ;-4,1885-1886$, etcétera.
} 
segundo tema presente de manera regular en la correspondencia del Consulado, ya fuera con propósitos solidarios, por las implicaciones que tenía para la seguridad de México o por los intereses comerciales de nuestro país. ${ }^{7}$

Otro de los temas relevantes, tratado reiteradamente, fue el de las relaciones con México, que revistieron un doble carácter: económico y político. En cuanto al primer aspecto, encontramos de manera constante durante todo el periodo que cubre la correspondencia, los reportes del movimiento marítimo entre los puertos mexicanos y el de La Habana, así como los informes acerca de los montos y productos del tráfico comercial que se llevaba a cabo con México. Los libros de registro de La Habana dan cuenta precisamente del tráfico entre aquel puerto y varios del litoral del Golfo mexicano, de Matamoros a Sisal. ${ }^{8}$

En el aspecto político, los temas fueron variando según el momento y la importancia de los asuntos la que delineó la correspondencia. En el conjunto de cuestiones tratadas destaca el problema de la migración de fuerza de trabajo maya a la isla antillana que constituyó, por cierto, uno de los puntos delicados de la relación entre México y Cuba. La correspondencia dedica algunas páginas a este acontecimiento y a su desarrollo y solución, ${ }^{9}$ así como a la situación de los residentes o de los asilados mexicanos en la isla ${ }^{10} \mathrm{y}$, en la

${ }^{7}$ AGN, L-(729.1-0)-3, 1901-1903.

${ }^{8}$ Por ejemplo, AGN, L-(729.1-5)-27, 1901 . 1902.

${ }^{9}$ AGN, L-(729.1-0)-2, 1899-1901; L(729.1-5)$36,1871 \cdot 1873 ;-4,1885-1886$, entre otros.

${ }^{10}$ La cercanía de'Cuba la convirtió en refu- contraparte, a las condiciones de vida y de trabajo de los cubanos que vinieron a México. ${ }^{11}$

El movimiento separatista de Yucatán y sus repercusiones aparecen mencionados con sumo cuidado en los despachos de los años cuarenta. ${ }^{12}$

Las cuestiones consulares ocupan muchas páginas de la documentación. Por tanto, hay gran cantidad de certificaciones de nacionalidad (que de. notan un movimiento continuo e importante de mexicanos por el área), ${ }^{13}$ recibos de envío de mercancías y manifiestos de tráfico de embarcaciones, manifiestos generales, facturas, registros de pasaportes, poderes y otros documentos, patentes de sanidad, matrículas, correspondencia con algunos viceconsulados, con autoridades de la isla y con el extranjero y, por supuesto, con el ministro mexicano de Relaciones Exteriores. ${ }^{14}$

En los tomos que resguardan las notas elaboradas hacia finales del siglo $\mathrm{XIX}$, encontramos una nueva línea temática que hace referencia a la imagen de México en el exterior. Sobre todo, en las cartas de la última década hay repetidas menciones acerca de la opi-

gio de muchos mexicanos de distinta filiación partidaria involucrados en la política interna quienes desde ahí enviaban proclamas, manifiestos, etc. AGN, L-(729.1-5)-38, 1878-1880.

${ }^{11}$ AGN, L-(729.1-0)-2, 1899-1901; L-(729.1-

$5)-23,1897-1898 ;-24,1888-1890 ;-28,1902$ 1903.

${ }^{12}$ AGN, L-(729.1-0)-35, 1838-1856.

13 AGN, L-(729.1-5)-11, 1888-1891.

${ }^{14}$ AGN, L-(729.1-0)-3, 1901-1903; L-(729.1. 5).5, 1892-1897; -6, 1897-1901;-11, 1888-1891; $-13,1886-1887$; -14, 1888-1890; -15, 1888-1889; $-25,1899-1905$. 
nión que sobre México y su gobierno se difundían en la isla. ${ }^{15}$

Por último, otro de los temas abordados en los documentos en cuestión, se refiere a los intereses geopolíticos de México por el área. De hecho, una de las mayores preocupaciones de México en las últimas décadas del siglo XIx fue la posible anexión de Cuba a Estados Unidos. El cónsul de México en La Habana, en ese entonces Don Andrés Clemente Vázquez, cruzó una nutrida correspondencia con el secretario de Relaciones Exteriores de México para informarle acerca de los avances en esa política y conocer las instrucciones que orientarían su actuación. Cuando consideró que eso no era suficiente y que la seguridad del país estaba comprometida, viajó a México para recibir los lineamientos que normaran su proceder. ${ }^{16}$

A la vuelta del siglo, hubo un cambio fundamental en la correspondencia, que bien pudo deberse a los diferentes intereses del gobierno mexicano. La correspondencia, antes detallada y fundamentalmente política, se dedicó casi de manera exclusiva a cuestiones administrativas y al envío de reseñas comerciales, con los datos acerca de los rubros y montos de las exportaciones de México hacia Cuba. ${ }^{17}$

15 AGN, L-(729.1-5)-15, 1888-1889; -17, 1890$1891 ;-31,1908-1909$.

16 AGN, L-(729.1-5)-35, 1838-1856;-16, 1889 . $1892 ;-17,1890-1891 ;-24,1888-1890$. 1902.

\section{LAS RELACIONES}

A partir del material informativo que ofrecen los distintos tomos de la correspondencia podrían desarrollarse varios temas de investigación: el desarrollo de Cuba en el siglo XIX, el movimiento anexionista cubano y los intereses mexicanos, las consecuencias de la guerra de Castas, las relaciones entre México y Cuba, etc. Nos interesa destacar, en este trabajo, algunas líneas que pueden seguirse para analizar el último tema señalado.

A primera vista, pareciera que en el siglo XIX las relaciones con el Caribe eran ajenas a los intereses de México. Sin embargo, en diferentes momentos de la vida política mexicana esas relaciones, y en particular con Cuba, fueron significativas para nuestra política exterior. Del gobierno de Iturbide al de Porfirio Díaz, la preocupación mexicana por Cuba obedeció a diferentes intereses: ya fuera para preservar la integridad nacional, proteger el comercio, impedir el contrabando, reafirmar la solidaridad, fomentar la cooperación, etc. Sin embargo, el principaly más constante interés fue la pretensión de resguardar la seguridad del país, del asedio español en los primeros años de vida independiente, de las ambiciones de potencias extranjeras más adelante, y hacia finales del siglo XIX, de las desembozadas acciones de Estados Unidos.

El interés mexicano por Cuba tuvo en el siglo XIX dos grandes momentos divididos por el reconocimiento español a la independencia de México. En la primera etapa, anterior al reconocimiento, el interés de México por la isla 
fue más activo y estuvo encaminado a que aquélla lograra su emancipación del dominio colonial español. En la segunda etapa, los vínculos con Cuba se inscribieron en el marco de las relaciones oficiales con España, adquirieron un carácter diplomático y todas las acciones abiertas de apoyo oficial a la lucha independentista de la isla fueron abandonadas. Los gobiernos mexicanos adoptaron una posición de neutralidad ante los disturbios domésticos cubanos. La valiosa perspectiva de conjunto que ofrece la nutrida colección se refiere a este segundo periodo, iniciado después del reconocimiento español.

Aunque el primer encargado del Consulado, Don Manuel Céspedes, fue designado en $1837,,^{18}$ las relaciones oficiales se iniciaron en realidad al año siguiente cuando Juan Fernández de la Vega y Mata fue nombrado y reconocido como cónsul mexicano en La Habana. ${ }^{19}$ Desde entonces y hasta que la embajada fue establecida en los primeros años del siglo $\mathrm{XX}$, hubo en todo momento una oficina consular en La Habana encargada de realizar diferentes tareas y trámites, lo que habla de relaciones constantes, incluso en épocas en que México y España no tuvieron relaciones.

¿Qué buscaba México al entablar relaciones con Cuba? Del análisis de la correspondencia enviada a la cancille-

18 Don Manuel Céspedes no fue reconocido por las autoridades españolas como cónsul mexicano porque era cubano de nacimiento.

${ }^{19}$ Además de la correspondencia, véase también Los primeros consulados de México 1823 1872, SRE, México, 1974 (Colección Archivo Histórico Diplomático). ría identificamos la índole diversa de sus intereses:

a) Preservar la seguridad del país. Nunca dejó de considerarse al Caribe, y en especial a Cuba, una región de la que dependía la seguridad de México. Cualquier cambio en la relación de $\mathrm{Cu}$ ba con otros países podía afectar la situación mexicana, sobre todo si Estados Unidos se apoderaba de la isla. ${ }^{20}$

b) Obtener información. Tanto de la situación política interna de la isla como de los movimientos de los países extranjeros en la región. Al revisar la correspondencia, encontramos que una de las principales funciones del Consulado mexicano era servir de puesto de observación desde el cual se informara a México acerca de los acontecimientos políticos locales y de la región en general, de los vaivenes de la política internacional $e$, incluso, de la repercusión que en ella tenía lo ocurrido en Europa. ${ }^{21}$ Para ello, se requería de los informes políticos, las reseñas económicas, la remesa de periódicos publicados en la isla y de cuanta nota hiciera referencia a los temas citados, todo lo cual le permitía a la Cancillería formarse una opinión acerca del momento político que se vivía y de las posibles implicaciones en la formación y consolidación del Estado nacional y le daba, asimismo, elementos para normar su actividad.

c) Procurarse reconocimiento. Esto fue particularmente evidente durante el conflicto entre liberales y conserva-

${ }^{20}$ AGN, L-(729.1-0)-3, 1901-1903; -12, 1887 1888; L-(729.1-5)-19, 1891-1892;-20, 1895-1896.

${ }^{21}$ AGN, L-(729.1-5)-35, 1838-1856; -36, 1871$1873 ;-16,1889-1892 ;-27,1901-1903$. 
dores, al iniciarse la segunda mitad del siglo XIX. Ambos grupos y sus gobiernos paralelos, el liberal de Juárez y el conservador de Zuloaga, nombraron representantes en la isla para hacerse cargo de las tareas inherentes al Consulado y con objeto de recabar el reconocimiento para sus respectivos gobiernos. El gobierno español reconoció primero al gobierno conservador y, en su momento, al imperio de Maximiliano.

d) Limitar el contrabando. Mediante el establecimiento de viceconsulados en el Caribe en general y en varias ciudades portuarias de Cuba, se intentó controlar el tráfico comercial y marítimo en la región pues a partir de la década de 1840 , la desastrosa situación económica del erario nacional era mayory la recaudación de las aduanas del Golfo, donde se encontraban los puertos marítimos más importantes por el volumen del tráfico comercial, era cada vez menor.

e) Recaudar ingresos. Sin pretender afirmar que las oficinas consulares en las islas del Caribe eran un sostén para el erario nacional, sí podemos decir que uno de los criterios para establecer oficinas consulares fue tratar de recuperar los ingresos que se perdian porque no se tenía un buen control sobre el tráfico comercial legal y, por supuesto, menos del ilegal, que se movía por el Caribe. La oficina de La Habana fue una de las que mejor cumplieron esa función, logrando ingresos importantes durante varios años. De hecho, el Consulado de La Habana es uno de los mejores ejemplos de una oficina recaudadora de recursos para la Hacienda mexicana. Situación de bonanza registrada en los cortes de caja enviados a la Secretaría de Relaciones Exteriores, ${ }^{22}$ que se transformó en saldos negativos al entrar en funcionamiento la red ferrocarrilera que unió a México con Estados Unidos, transportando volúmenes importantes de mercancías: materias primas en un sentido, y bienes manufacturados en el contrario. ${ }^{23}$

f) Mantener el tráfico comercial y maritimo entre ambos países. Cuba era la intermediaria del comercio español con América y el paso obligado de las rutas marítimas que unían a México y a Europa. El intercambio comercial de México con Cuba se incrementó considerablemente y La Habana fue el puerto más importante para ese comercio durante todo el siglo $\mathrm{XIX} \cdot{ }^{24}$ Las relaciones de buques que entraban y salían de los puertos cubanos procedentes de o con destino a México se enviaban con cierta periodicidad. 25

Las reseñas comerciales elaboradas por el Consulado mexicano en La Habana informan acerca de los montos y gran variedad de artículos que México exportaba a la isla por esos años, entre ellos productos agrícolas (henequén, frijol, ajo, café, garbanzo, plátano, etc.) y ganado (caballos, asnos, mulas y va-

22 AGN, L-(729.1-0)-3, 1901-1903.

${ }^{23}$ AGN, L-(729.1-0)-2, 1899-1901.

${ }^{24}$ Por lo menos, ya lo era en los años veinte y para los setenta, seguía manteniendo su importancia. Véase Inés Herrera Canales, $E l$ comercio exterior de México. 1821-1875, El Colegiode México, México, 1977 (Centrode Estudios Históricos. Nueva Serie 25).

${ }^{25}$ AGN, L-(729.1-0)-2 1899-1901; L-(729.1-5). $24,1888-1890 ;-27,1901-1902$. 


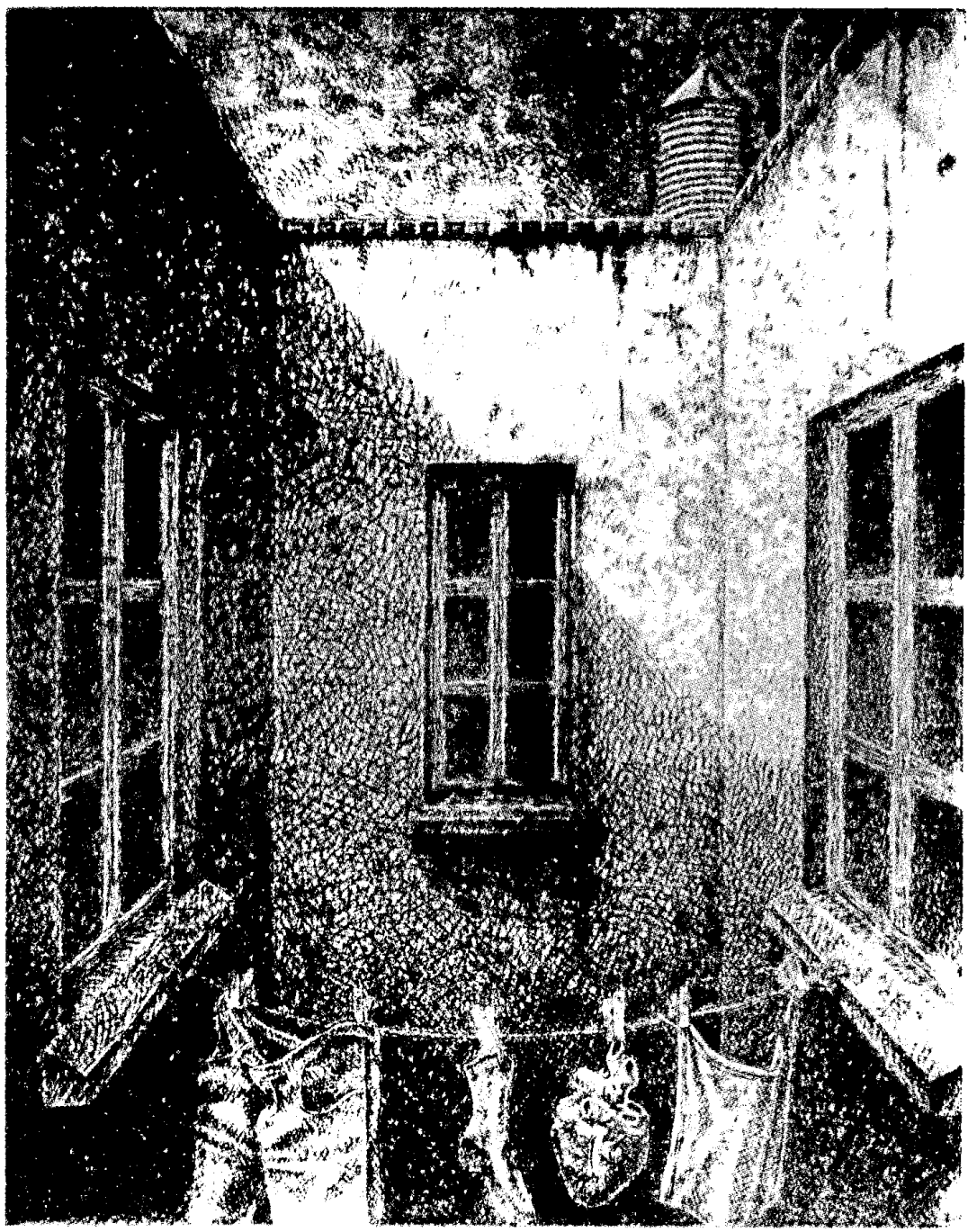

Grabados del Taller Tiempo Extra Editores. Fotografía de Mónica Velasco.

Queda estrictamente prohibida la reproducción total o parcial

de las imágenes publicadas en este número de la revista Secuencia, 36.

Las imágenes fueron contratadas y/o donadas de forma exclusiva para esta publicación. 
cas). Entre las importaciones mexicanas destacan aceitunas, pasas, cigarrillos y puros, así como muebles para la vida cotidiana, tejidos, encajes y utensilios. Los puertos dedicados a ese comercio que era trasladado por embarcaciones estadunidenses, noruegas, inglesas, españolas, francesas y alemanas fueron Progreso, Campeche, Tlacotalpan, Veracruz y Tampico. ${ }^{26}$

g) Interés geopolítico por el área. En el siglo XIX, la supervivencia politica y el establecimiento del Estado nacional fueron los objetivos fundamentales de México. Para ello debió desplegar hábilmente, entre otras cosas, una política exterior apropiada. En ella el Caribe no fue la región prioritaria, pero en la medida en que era la llave de acceso al territorio, nunca fue desatendida. Cuba era importante por su posición geográfica, en la cual contaba la significación política y que fuera, además, paso de la ruta marítima comercial. Aunque México no tuviera recursos para sostener una presencia en el área, no podía obviar la importancia que dicha zona tenía para países más desarrollados de Europa, y en especial para Estados Unidos, que al apoderarse de la isla cerrarían la salida natural de México. Así pues, hacia la segunda mitad del siglo XIX, paralelamente a la política estadunidense cada vez más agresiva e interesada en la zona del Caribe y en particular en $\mathrm{Cu}$ ba, México, para mantener su preséncia en el área, aprovechó el establecimiento de los viceconsulados. En la isla, los de Puerto Cárdenas (1859), Santiago (1860), Matanzas (1853) y

$$
{ }^{26} \text { AGN, L-(729.1-5)-26, 1901-1902. }
$$

Trinidad, ${ }^{27}$ y en general, en la región caribeña, los de Carlota Amalia en Saint Thomas (1855); Fort de France, Martinica (?); San Juan de Puerto Rico (1848), y Kingston, en Jamaica (1855). Hacia finales del siglo $\mathrm{xIx}$, durante el régimen porfirista, el gobierno mexicano extendió el establecimiento de oficinas comerciales y consulares en la región caribeña. ${ }^{28}$

El interés por Cuba a fines del siglo XIX readquirió importancia geopolítica para México, que buscaba jugar el papel de "potencia media" en el área en función de la relación con Estados Unidos y de la defensa de la soberanía, ligada en cierta medida, según se creía, a la suerte de la región.

Las representaciones se hicieron a cuenta de ricos comerciantes locales que pagaban la instalación de las oficinas y se hacían cargo de la representación enviando continuamente informes políticos, además de extender las patentes necesarias a las embarcaciones, los pasaportes a los viajeros, defender a mexicanos en determinadas situaciones, hacerse cargo de algunos trámites jurídicos, impulsar el comercio de esas islas con México, etc. ${ }^{29} \mathrm{Va}$ -

${ }^{27}$ AHSRE, exp. LE 1796(1). Desde 1853 había sido vicecónsul en Matanzas Juan Crespo de la Serna. Le sucedió en 1860, León Crespo. En 1860 en Santiago, el vicecónsul fue Juan Rafecas.

${ }^{28}$ Laura Muñoz, El Caribe en la perspectiva mexicana, XVIII conferencia de la Caribbean Studies Association celebrada en Kingston-Ocho Ríos, Jamaica, del 23 al 28 de mayo de 1993. Una versión corregida aparecerá en la revista Homines, de Puerto Rico.

29 Podemos citar entre esos ricos comerciantes que ejercieron el cargo de cónsules o vicecónsules a: Francisco Antonio de Bada, en Saguá la Grande (1901); Pablo Bory de la Cruz, en San- 
rias de esas representaciones empezaron como oficinas comerciales. Los encargados no eran en realidad diplomáticos representando a un país; no obstante, en más de una ocasión excedieron el ámbito consular y actuaron como diplomáticos. De hecho, a principios de la década de 1890, el cónsul A. C. Vázquez fue nombrado decano del cuerpo diplomático acreditado en La Habana.

Casualidad o no, en los casos en que los encargados no eran comerciantes, sus informes fueron mejores. La percepción de la labor que debían cumplir y de los objetivos a lograr respondió adecuadamente a los intereses de los gobiernos mexicanos. Entre los miembros de este grupo, podemos citar a Buenaventura Vivó, uno de los primeros en no conformarse con una actuación meramente administrativa; a Ramón Carballo, de tendencia conservadora, pero atento desde su perspectiva a los intereses de México en la región y, por supuesto a Don A.C. Váz. quez, que se comportó siempre como un diplomático, y aunque haya cumplido también con las funciones de agente comercial, su principal característica fue la defensa de los intereses mexicanos en la región. Sus despachos son precisos, lúcidos y retratan al diplomático que fue.

tiago de Cuba; José Ma. Alonso, comerciante comisionista y corredor de buques, en Cienfuegos; Leandro González Alcorta en Pinar del Río; Antonio Ramos Valderas en Santa Clara y en Matanzas Agustín Penichet (1903); Miguel Lluría en Cárdenas (1902-1907), y Miguel Muñiz y Pla, en Manzanillo (1908-1909).

\section{CONCLUSIONES}

Son pocos los documentos que en forma aislada tienen una significación especial y valiosa, pero en conjunto nos proporcionan una visión integral de una relación que fue constante durante todo el siglo XIX, a diferencia de lo que ocurrió con otros países latinoamericanos y del Caribe.

Si bien es cierto que México no tenía ambiciones expansionistas por la región del Caribe, es indudable que le interesaba tener una presencia allí. Esa actitud se pone de manifiesto en la documentación reunida en el fondo comentado. Destaca en todo el material reunido en los libros copiadores, la actitud oficial mexicana de neutralidad hacia Cuba y la estrategia seguida en las relaciones con la isla, caracterizada por la negociación diplomática en todos aquellos casos que ameritaban una definición política de México.

INVENTARIO DE LA CORRESPONDENCIA DEL CONSULADO MEXICANO en la Habana, 1838-1922

La correspondencia del Consulado mexicano en La Habana pertenece al fondqdocumental Relaciones Exteriores. Para elaborar el inventario se respetó la clasificación creciente original, que no responde a una secuencia cronológica. Se adjunta, al final, una lista ordenada cronológicamente.

L- (729.1-0) -2, 1899-1901.

Es uno de los libros con más información sobre los diversos temas que se tratan en la correspondencia: situación política de Cuba; los trabajadores mayas en la isla; 
cortes de caja; relación de buques despachados a México y notas sobre trámites consulares.

L- (729-1-0) -3, 1901-1903.

El libro contiene cortes de caja y notas sobre trámites consulares. Uno de los temas fundamentales tratados en este tomo se refiere a los intereses de México por la situación cubana y por la presencia estadunidense.

L- (729-1-0) -4, $1885-1886$.

Las notas de este libro tratan sobre cuestiones de sanidad (cuarentenas, campañas de salud, etc.). También se habla de la emigración de cubanos a Yucatán y de los trámites para la protección a mexicanos en Cuba. Destaca el análisis de la situación económica de la isla.

L- (729.1-5) -5, 1892-1897.

Registro detallado y cuidadoso de los ingresos y egresos del Consulado. Contiene notas sobre trámites consulares.

L. (729-1-5) -6, 1897-1901.

Informes de las embarcaciones que hacían las travesías a puertos mexicanos; informes de los ingresos económicos y actividades del Consulado.

L- (729.1-5) -7, 1904-1905.

Es un libro incompleto con gran cantidad de hojas desprendidas. Contiene notas sobre trámites consulares.

L- (729.1-5) -9, 1907-1908.

Fundamentalmente reúne informes politicos.

L. (729.1-5) -10, 1917-1918.

Índice de la correspondencia enviada por el Consulado mexicano en los dos años señalados.

L- (729.1-5) -11, 1888-1891.

Reúne certificaciones y notas sobre otros trámites consulares.

L- (729.1-5) -12, 1887-1888. (reservado) El tema más importante de la correspondencia de este volumen es la posible anexión de Cuba a Estados Unidos. Hay informes políticos sobre la isla, reportes de embarcaciones y notas consulares.
L- $(729.1-5) \cdot 13,1886-1887$.

Notas consulares e informes políticos y económicos de Cuba.

L. (729.1-5) -14, 1888-1890.

Notas de trámites consulares.

L. (729.1-5) - 15, 1888-1889.

Reporte sobre embarcaciones cuyo destino eran los puertos mexicanos, cuestiones de sanidad, situación del Consulado, cortes de caja y cambios políticos en la isla. Noticias sobre México y opinión sobre el país.

L- (729.1-5) -16, 1889-1892.

Varias misivas sobre la posible anexión de Cuba a Estados Unidos, situación de la isla y relación con España. Contiene informes sobre la región y noticias sobre México publicadas en los periódicos cubanos. Cortes de caja.

L. (729.1-5) -17, 1890-1891.

Opiniones de los periódicos cubanos sobre la situación de México. Noticias acerca de la posible anexión cubana a Estados Unidos. Gran cantidad de despachos que revelan el interés mexicano por Cuba y su desarrollo económico y poli. tico. Cortes de caja.

L- (729.1-5) -18, 1891-1893.

Básicamente cortes de caja, y manifiestos de las embarcaciones que se dirigían a puertos mexicanos.

L- (729.1-5) -19, 1891-1892.

Correspondencia acerca de cuentas y cortes de caja, gastos de oficio, temores por la revolución en Cuba, crisis monetaria en la isla, noticias de viceconsulados, impresos interesantes, varias notas sobre enfermedades epidémicas de la época.

L- (729.1-5) - 20, 1895-1896.

Acerca de la revolución en la isla y la posición oficial que México debería adoptar. Cortes de caja.

L- (729.1-5) -21, 1896-1897.

Texto en mal estado. Notas consulares.

L- (729.1-5) -22, 1896-1898.

Notas acerca de la insurrección en Cuba. Asimismo se hace referencia a la cues- 
tión monetaria en la isla y a las posibles repercusiones en el comercio entre Cuba y México. Cortes de caja.

L- (729.1-5) -23, 1897-1898.

Algunos de los temas tratados en este volumen son: Cuba y Estados Unidos, condiciones de vida de trabajadores cubanos en México, comercio entre México y la isla, cortes de caja, etcétera.

L- (729.1-5) -24, 1888-1890.

Informes mensuales de movimiento marítimo, informes sobre la autonomía de Cuba, noticias sobre México, situación política de la isla e intereses de México, emigración de cubanos a México, cortes de caja, la guerra entre Estados Unidos y España.

L- (729.1-5) -25, 1899-1905.

Contiene cortes de caja y notas sobre trámites consulares.

L- (729.1-5) -26, 1901-1902.

Reseñas comerciales de la isla, movimiento marítimo, cortes de caja, tráfico de esclavos negros a Yucatán, montos de importaciones de México hacia Cuba.

L- (729.1-5) -27, 1901-1902.

Reseñas comerciales, movimiento marítimo, informes sobre la actividad comercial entre México y la isla, cortes de caja e informes sobre la situación interna de la isla, elección de Estrada Palma y formación de su gabinete.

L- (729.1-5) - 28, 1902-1903.

Asuntos consulares e información comercial.

L- (729.1-5) -29, 1906-1907.

Situación económica y política de Cuba, informes acerca del protectorado norteamericano, cortes de caja y gran cantidad de cartas a diferentes puertos mexicanos.

L- (729.1-5) -30, 1906-1907. Notas consulares.

L- (729.1-5) -31, 1908-1909.

Noticias sobre México, informes acerca de las actividades económicas y situación política de Cuba.
L- (729.1-5) -32, 1909-1910.

El volumen recoge las carta que se enviaban del Consulado a otros consulados o a particulares. Hay referencias al impulso otorgado al tráfico comercial.

L- (729.1-5) -33, 1922.

Libro de caja.

L- (729.1-5) -34, 1877 (aunque la tapa dice 1887).

Casi todo el tomo es correspondencia enviada al Consulado por la Cancillería mexicana.

L- (729.1-5) -35, 1838-1856.

Es uno de los volúmenes más importantes de la colección. Ofrece información detallada de varios años, a partir del establecimiento del Consulado. Hay reportes de los movimientos de potencias extranjeras en el Caribe, reseñas del desarrollo económico de Cuba enviadas regularmente, notas relacionadas con el comercio y transporte de mercancías, informes políticos, registro de tráfico marítimo hacia México, presencia de exilados mexicanos en la isla, reseñas de acontecimientos en Yucatán y Campeche, notas acerca de la situación política de algunas islas de la región y de los movimientos en Nueva Orléans, noticias acerca de los enviados mexicanos a Washington, notas consulares.

L- (729.1-5) -36, 1871-1873.

Volumen elaborado por el representante del gobierno de Juárez en la isla. Existía una correspondencia paralela del gobier. no imperial. Este libro reúne reseñas de lasnoticias provenientes de Europa (guerra franco-prusiana), habla de la situación política de la isla de manera detallada y de la introducción de colonos mexicanos a Cuba, procedentes de Yucatán. La correspondencia de Hoffman Urquiza incluye noticias procedentes de América Latina, manifiestos y facturas.

L- (729.1-5) -37, 1876-1883.

Temas consulares en todo el volumen (protección a mexicanos, corresponden- 
cia oficial y con particulares, y sobre movimiento marítimo).

L- (729.1-5) -38, 1878-1880.

Temas consulares. Destaca la correspon. dencia acerca de los mexicanos en Cuba.

L- (729.1-5) -39, 1882.

Importante por la cantidad de reseñas comerciales y políticas enviadas mensualmente. Incluye correspondencia con temas consulares y acerca de los acontecimientos significativos en la isla, entre los que destaca la emigración china.

L- (729.1-5) -40, 1884-1889.

Reúne correspondencia minuciosa sobre la situación interna de Cuba y asuntos consulares firmada por el cónsul Andrés Clemente Vázquez.

L- (729.1-5) - 41, 1885-1886.

Se encuentran en este tomo varios manifiestos y cortes de caja. La correspondencia está firmada por Gilberto Crespo como cónsul. Hay un predominio de copias de certificaciones, noticias de entrada y salida de buques, informes de los pasaportes visados en el Consulado (consignando nombre, origen y destino). Se encuentran varias cartas que se ocupan de transmitir información acerca de cómo mejorar la agricultura y la ganadería.

L- (729.1-5) -42, $1885-1886$.

Libro copiador de la correspondencia del Consulado con las autoridades de la isla. Informa además sobre trámites consulares, jurídicos, testamentaría, manifiestos, etcétera.

L- (729.1-5) -43, 1888-1891.

Este volumen reúne cortes de caja y manifiestos.

L- (729.1-5) -44, 1901.

Se trata fundamentalmente de la correspondencia del Consulado con las autoridades mexicanas sobre diversos temas. Otra parte de las cartas hace referencia a problemas consulares.

L. (729.1-5) -45, 1901-1905.

Son acuses de recibo de correspondencia y trámites consulares. Es el primer tomo en el que la correspondencia está escrita a máquina.

L- (729.1-5) -46, 1902-1904.

Este volumen está constituido por la correspondencia que da cuenta de los trámites consulares, el intercambio epistolar con los viceconsulados en otras ciudades cubanas y por cortes de caja.

L. (729.1-5) -47, 1902-1904.

Este tomo también concentra las comunicaciones acerca de asuntos consulares, correspondencia con otras oficinas e información.

L- (729.1-5) -48, 1902-1905.

Se recopilan en este tomo fundamentalmente documentos consulares.

L- (729.1-5) -49, 1903-1904.

Algunos de los temas tratados en la correspondencia de este volumen son: consulares (diligencias para auxiliar a compatriotas mexicanos en Cuba, inmigrantes para México, movimientos de buques, intestados), información económica (revista mercantil de la situación cubana) e información sobre la isla. La correspondencia está firmada por el cónsul Palomino.

L- (729.1-5) -50, 1905-1906.

Como en los anteriores volúmenes, la correspondencia concentra informes económicos, cortes de caja, reportes acerca del movimiento de buques, otros asuntos consulares, información económica sobre Cuba (cuestión bancaria) e informes políticos. Destaca la información acerca de las deciaraciones del presidente estadunidense Roosevelt.

L- (729.1-5) -51, 1906-1909.

Último de los tomos de la correspondencia remitida por el Consulado de México en La Habana. Reúne cortes de caja, reportes del movimiento marítimo hacia México, acerca del control de la fiebre amarilla y la correspondencia con autoridades mexicanas, principalmente con la Secretaría de Hacienda.

Aunque hay algunos tomos cuyos años se 
sobreponen, el orden cronológico de los libros copiadores de la correspondencia del consulado es el siguiente:

L-(729.1-5)-35, 1838-1856.

L-(729.1-5)-36, 1871-1873.

L-(729.1-5)-37, 1876-1883.

L-(729.1-5)-34, 1877.

L-(729.1-5)-38, 1878-1880.

L-(729.1-5)-39, 1882.

L-(729.1-5)-40, 1884-1889.

L-(729.1-5)-4, $1885-1886$.

L-(729.1-5)-41, 1885-1886.

L-(729.1-5)-42, 1885-1886.

L-(729.1-5)-13, 1886-1887.

L-(729.1-5)-12, 1887-1888.

L-(729.1-5)-15, 1888-1889.

L-(729.1-5)-14, 1888-1890.

L-(729.1-5)-24, 1888-1890.

L-(729.1-5)-11, 1888-1891.

L-(729.1-5)-43, 1888-1891.

L-(729.1-5)-16, 1889-1892.

L-(729.1-5)-17, 1890-1891.

L-(729.1-5)-19, 1891-1892.

L-(729.1-5)-18, 1891-1893.

L-(729.1-5)-5, $1892-1897$.

L-(729.1-5)-20, 1895-1896.
L-(729.1-5)-21, 1896-1897.

L-(729.1-5)-22, 1896-1898.

L-(729.1-5)-23, 1897-1898.

L-(729.1-5)-6, 1897-1901.

L-(729.1-5)-2, 1899-1901.

L-(729.1-5)-44, 1901.

L-(729.1-5)-25, 1899-1905.

L-(729.1-5)-26, 1901 a 1902.

L-(729.1-5)-27, $1901-1902$.

L-(729.1-5)-28, 1902-1903.

L-(729.1-5)-3, $1901-1903$.

L-(729.1-5)-45, 1901-1905.

L-(729.1-5)-46, 1902-1904.

L-(729.1-5)-47, 1902-1904.

L-(729.1-5)-48, $1902-1905$.

L-(729.1-5)-49, $1903-1904$.

L-(729.1-5)-7, $1904-1905$.

L-(729.1-5)-50, $1905-1906$.

L-(729.1-5)-29, $1906-1907$.

L-(729.1-5)-30, 1906-1907.

L-(729.1-5)-51, 1906-1909.

L-(729.1-5)-9, $1907-1908$.

L-(729.1-5)-31, 1908-1909.

L-(729.1-5)-32, 1909-1910.

L-(729.1-5)-10, 1917-1918.

L-(729.1-5)-33, 1922. 